\title{
Esthetic Rehabilitation with Immediate Implants in a Compromised Situation
}

\author{
${ }^{1}$ Anup Gopi, ${ }^{2} \mathrm{M}$ Viswambaran, ${ }^{3}$ Rakesh Kumar Dhiman, ${ }^{4}$ Dinesh Kumar Saini
}

\begin{abstract}
The end goal of prosthetic replacement of teeth following tooth loss is to provide a functional restoration that is harmonious with the remaining natural dentition. To achieve this goal, hard and soft tissues need to be present in adequate volume and quality. An increasingly common strategy to preserve bone and reduce treatment times includes the placement of dental implant into a fresh extraction site. Resorption of the alveolar bone is common after the extraction and presents a clinical challenge to ideal implant placement, especially in the esthetic zone. In order to preserve the extraction socket dimension, immediate implant placement at the time of extraction has been proposed. The technique involves atraumatic extraction of the tooth followed by implant placement. Voids between the implant and the socket walls are filled with a particulate bone graft material. This article describes one such case of immediate implant placement and prosthodontic rehabilitation of a young patient following traumatic loss of natural teeth.
\end{abstract}

Keywords: Immediate implant placement, Compromised bone, Custom milled abutment, Esthetic rehabilitation.

How to cite this article: Gopi A, Viswambaran M, Dhiman RK, Saini DK. Esthetic Rehabilitation with Immediate Implants in a Compromised Situation. Int J Oral Implantol Clin Res 2014;5(2): 60-62.

Source of support: Nil

Conflict of interest: None

\section{INTRODUCTION}

A common strategy to preserve bone and reduce treatment time includes the placement of dental implant into a fresh extraction site. ${ }^{1}$ The current increase in the use of endosteal implants directly into the extraction socket helps to preservation of the alveolar bone and ensures optimal implant placement. In order to preserve the extraction socket dimension, immediate implant placement has been proposed. ${ }^{2,3}$ This paper describes a case where dental implants were placed in fresh extraction socket in the esthetic zone in a situation with compromised bone levels and restored esthetically with all porcelain fused to metal crowns.

\footnotetext{
${ }^{1}$ Resident, ${ }^{2,3}$ Associate Professor, ${ }^{4}$ Reader

${ }^{1-4}$ Department of Dental Surgery, Armed Forces Medical College Pune, Maharashtra, India
}

Corresponding Author: Anup Gopi, Resident, Department of Dental Surgery, Armed Forces Medical College, Pune-411040 Maharashtra, India, Phone: 91-7588624374, e-mail: anup. gopi@yahoo.in

\section{CASE REPORT}

A 20-year-old medical cadet was referred to the Division of Prosthodontics 24 hours following trauma from the medical inspection room for evaluation. On extraoral examination, the patient had lacerations on his upper lip (Fig. 1) which was sutured with size 3-0 absorbable suture. Intraoral examination revealed broken root stump in relation to 21 with pain on percussion on 22 and 23. OPG was taken which revealed a root stump in relation to 21 with fracture of the marginal labial cortical plate and a horizontal fracture of 23 about $3 \mathrm{~mm}$ apical to the marginal bone (Fig. 2). The patient had a high lip line with a group function occlusion bilaterally. Case was taken up for rehabilitation with immediate implant placement using two stage surgical technique after investigations. The procedure was explained to the patient in detail and consent obtained. The root stump in relation to 21 and the fractured tooth in relation to 23 were extracted atraumatically (Fig. 3). Osteotomy was done and implants (XIVE plus, Friadent, Dentsply) of diameter $5.5 \mathrm{~mm}$ and length $13 \mathrm{~mm}$ was placed in the region of 21 and implant (XIVE plus, Friadent, Dentsply) of diameter $4.5 \mathrm{~mm}$ and length $15 \mathrm{~mm}$ was placed in the region of 23 . Considering the fractured labial cortical plate the implant in the region of 21 was placed slightly palatal to the ideal position and the defect on the labial surface was augmented with demineralized freeze dried bone allograft (Dembone, Los Angeles) and resorbable membrane (Bioguide) (Fig. 4). Placement of implant on 23 was further challenging considering the fact that the fractured segment was removed from a position 2-3 mm apical to the marginal bone. Complete closure of the wound was achieved with nonabsorbable 3-0 silk sutures. Adequate postinsertion instructions were given and the patient was temporarily rehabilitated using a resin retained provisional restoration with adequate relief over the region of the implants. Healing period was uneventful and radiological evaluation was done after a period of 6 months, which revealed complete osseointegration. After minimal exposure of the of implant, sealing screw was removed and gingival former placed. Stability was checked using a resonance frequency analyser and a gingival former was placed to achieve good gingival contour around the implant. After 3 weeks the gingival former was removed and the implant abutment was placed and evaluated for esthetics. Considering the angulation of the implant in 21, the metallic 


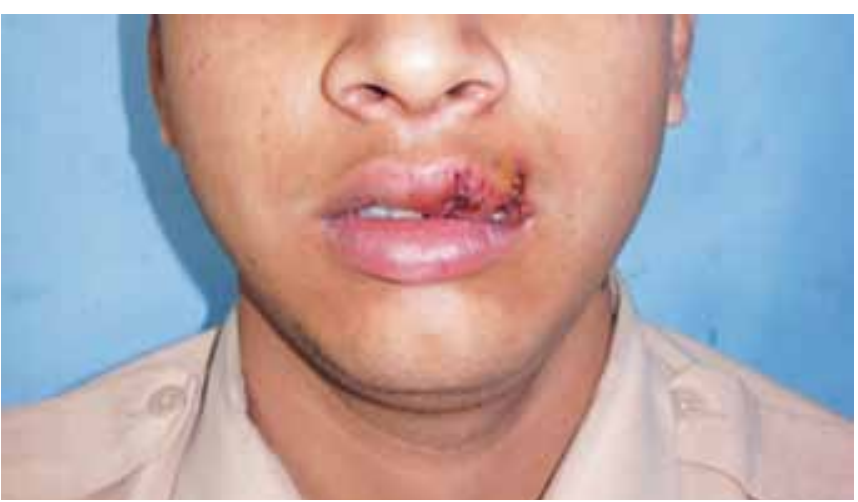

Fig. 1: Preoperative photograph

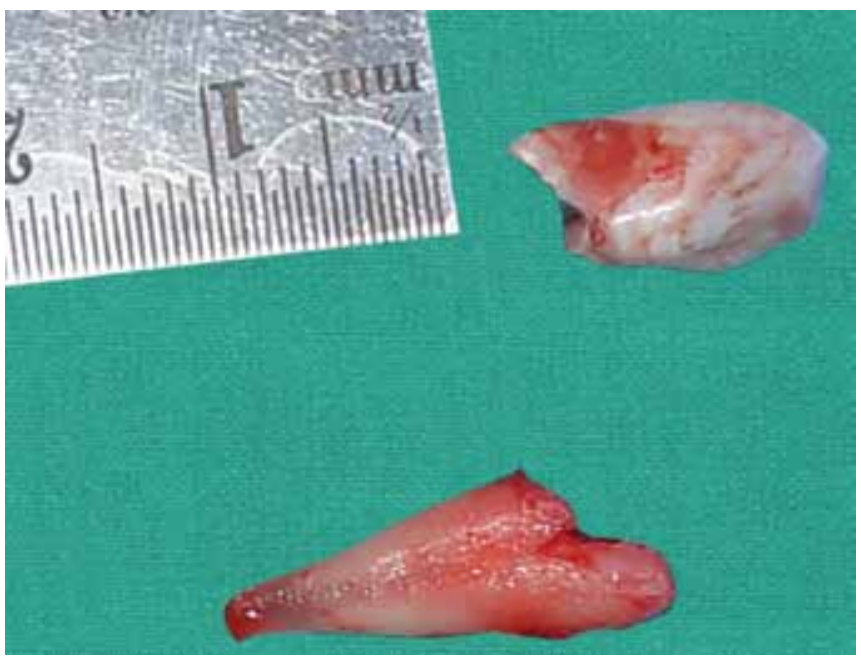

Fig. 3: Atraumatic extraction of fractured tooth

collar of abutment was visible incisal to the marginal gingiva. This abutment collar was custom milled to allow for adequate bulk of the prosthetic superstructure within the esthetically acceptable limits. Considering that the crown height available was adequate a cement retained prosthesis was planned. Impression was made with addition silicone using the closed tray technique. Metal coping trial was done to once again ascertain the esthetics and a porcelain fused to a metal restoration was fabricated. This was luted temporarily and the patient was evaluated for a period of 4 weeks followed by permanent luting (Fig. 5). Group function type of occlusion was maintained postoperatively. Postoperative radiograph revealed well-osseointegrated implants perfectly aligned with the natural dentition (Fig. 6). The natural smile of the patient was also restored back effectively (Fig. 7).

\section{DISCUSSION}

The technique of immediate implant placement involves atraumatic extraction of the tooth followed by implant placement. Voids between the implant and the socket walls are filled with a bone graft material. Advanced periodontal attachment loss, tooth fractured beyond the cervical line, teeth restored with crowns, loosened endodontic posts,

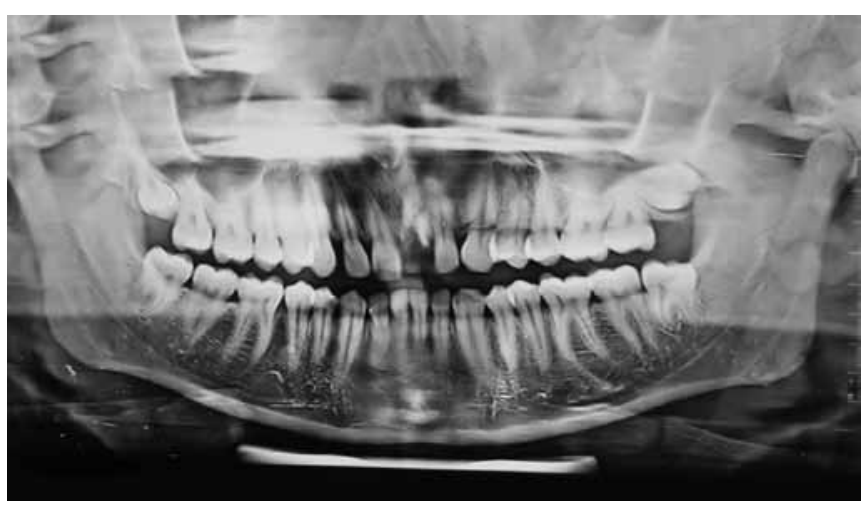

Fig. 2: Preoperative radiograph

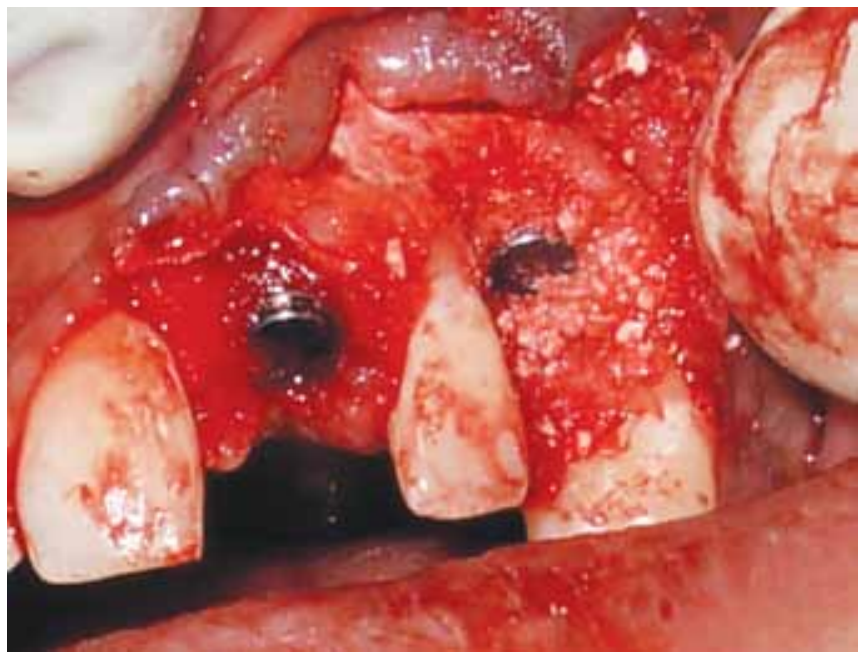

Fig. 4: Implants with bone graft in situ

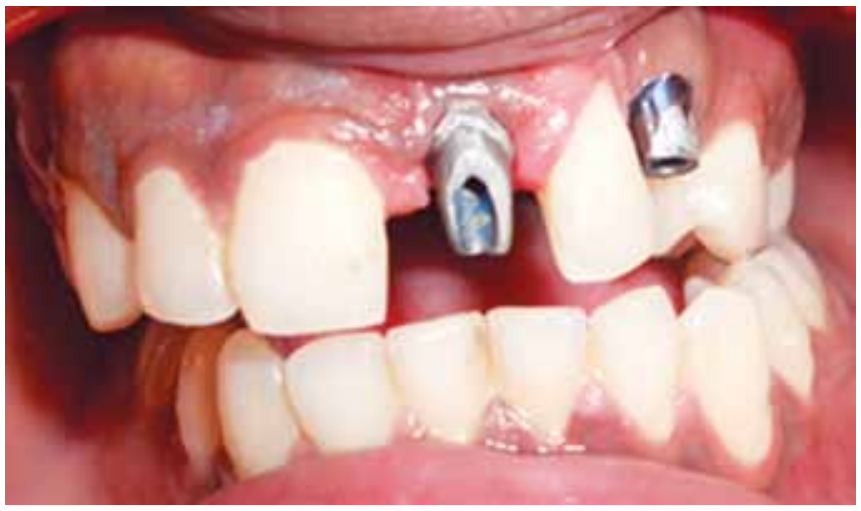

Fig. 5: Custom milled abutment

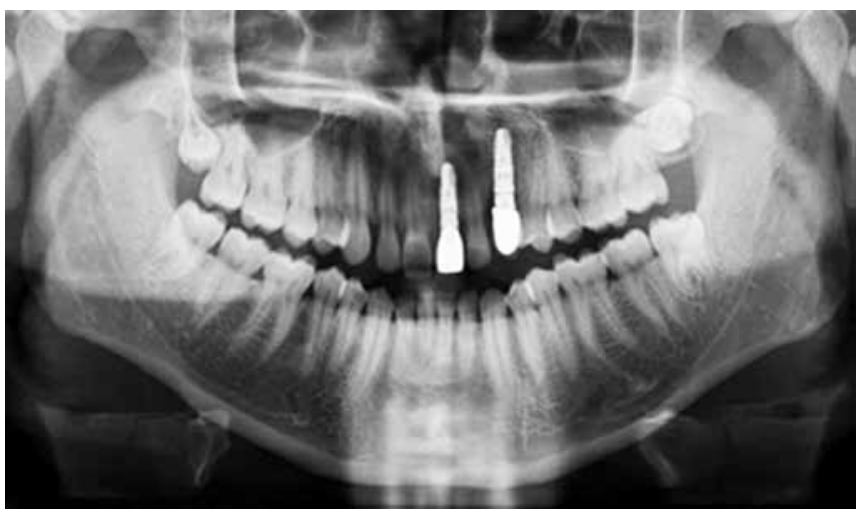

Fig. 6: Postoperative radiograph 


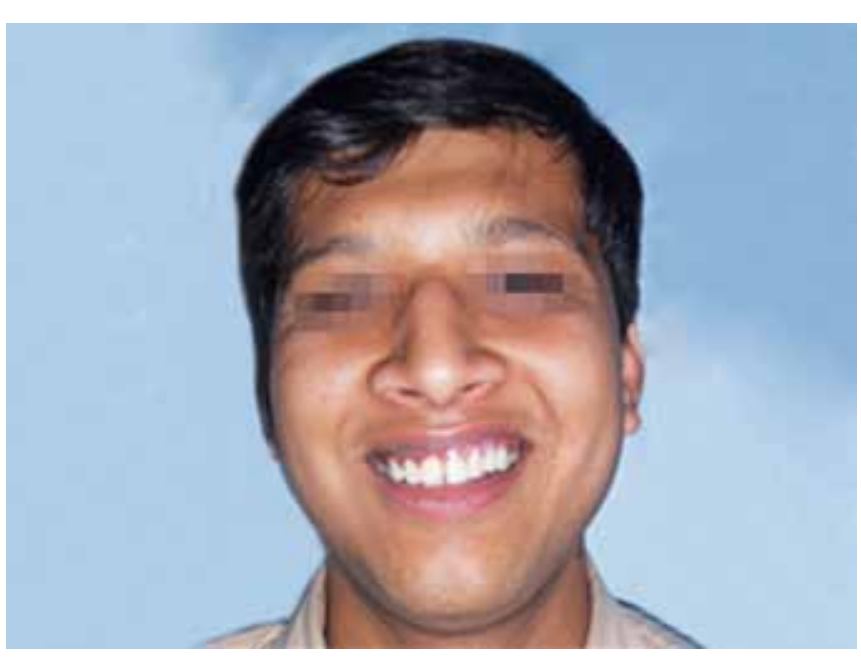

Fig. 7: Postoperative photograph

advanced caries, unfavorable crown-to-root ratios, and various combinations of these factors contribute to a final decision to remove teeth. These factors ultimately affect the total treatment plan. In the esthetic zone bone morphology, scalloping of marginal gingiva, level of crestal and interproximal bone and smile line must be considered before initiating treatment. ${ }^{4}$ Initial implant stability is the most critical factor in implant osseointegration. ${ }^{5}$ Thus, an ideal situation is one that has good amount of alveolar bone enabling the implant to have maximum primary stability.

The main advantage of placing immediate implants is the reduction in time of therapy, reduction in surgical episodes and preservation of the bone and gingival tissues. ${ }^{6}$ Greater rate of bone resorption occurs during the first 6 months following tooth extraction, unless an implant is placed or a socket augmentation procedure performed. ${ }^{7}$ The early maintenance of the gingival form greatly facilitates the peri-implant gingival tissue esthetics by maintaining support for the interdental papillae. Aside from the biological advantages of immediate implant placement, there are also psychological advantages. Although many patients readily accept delayed implant placement, some find it difficult to face the prospect of waiting up to 6 months for an extraction site to heal followed by an additional 3 to 6 months for the implant to osseointegrate. In clinical practice, there often arises a situation when one is not able to place an immediate implant, even though it was planned or when successful placement cannot be guaranteed. Factors such as tooth ankylosis, fracture of the buccal plate, socket expansion during extraction, or extensive infection might make immediate implant placement impossible or less predictable.

Disadvantages of immediate implant placement include the following:

i. Lack of control of the final implant position

ii. Difficulty obtaining primary stability

iii. Inadequate soft tissue coverage

iv. Inability to inspect all aspects of the extraction site for defects or infection

v. Difficulty in preparing the osteotomy due to bur movement on the walls of the extraction site

vi. The added cost of bone grafting. While all the disadvantages listed are not present in every situation, any factor mentioned above can result in a compromised case.

\section{CONCLUSION}

In the case of immediate implant, the patient is rehabilitated in lesser time with simultaneous placement of implant with no additional surgical requirement. A long-term functional and esthetic rehabilitation can be achieved in just a few months compared to rehabilitation using a conventional implant placement procedure.

\section{REFERENCES}

1. Lazzara RJ. Immediate implant placement into extraction sites: surgical and restorative advantages. Int J Periodontics Restorative Dent 1989;9:332-343.

2. Parel SM, Triplett RG. Immediate fixture placement: a treatment planning alternative. Int J Oral Maxillofac Implants 1990;5: 337-345.

3. Kan JY, Rungcharassaeng K, Umezu K, Kois JC. Dimensions of peri-implant mucosa: an evaluation of maxillary anterior single implants in humans. J Periodontol 2003;74:557-562.

4. Fugazzotto PA. Implant placement in maxillary first premolar fresh extraction sockets: description of technique and report of preliminary results. J Periodontol 2002;73:669-674.

5. Wilson TG Jr, Schenk R, Buser D, et al. Implants placed in immediate extraction sites: a report of histologic and histometric analyses of human biopsies. Int J Oral Maxillofac Implants 1998;13:333-341.

6. Wagenberg BD, Ginsburg TR. Immediate implant placement on removal of the natural tooth: retrospective analysis of 1,081 implants. Compend Contin Educ Dent 2001;22(5):399-402.

7. Schwartz-Arad D, Chaushu G. The ways and wherefores of immediate placement of implants into fresh extraction sites: a literature review. J Periodontol 1997;68:915-923. 